\title{
Studi Fitokimia pada Jahe Merah (Zingiber officinale Roscoe Var. Sunti Val)
}

\author{
Irma Erika Herawati1, ${ }^{*}$, Nyi Mekar Saptarini² \\ 1Jurusan Farmasi, FMIPA Universitas Al-Ghifari, Bandung, Jawa Barat \\ 2Departemen Farmasi Kimia Analisis, Fakultas Farmasi, Universitas Padjadjaran, Sumedang, \\ *Email korespondensi: irmaerikaherawati@unfari.ac.id
}

(Submit 15/03/2019, Revisi 05/09/2019, Diterima 20/12/2019)

\begin{abstract}
Abstrak
Jahe merah merupakan tanaman obat berupa tumbuhan rumpun berbatang semu, termasuk keluarga Zingiberaceae. Jahe merah banyak dimanfaatkan untuk mengobati berbagai macam penyakit seperti masuk angin, gangguan pencernaan, antipiretik, antiinflamasi, dan juga analgesik. Penelitian ini bertujuan untuk mengetahui kadar flavonoid dari jahe merah, identifikasi senyawa flavonoid, dan aktivitas antioksidan dari jahe merah. Metode ekstraksi yang digunakan adalah refluks dengan campuran pelarut etanol $96 \%: \mathrm{HCl}$ 12N. Metode pengujian kadar flavonoid dilakukan dengan menggunakan metode komplek flavonoid: $\mathrm{AlCl}_{3}$. Pemisahan senyawa flavonoid dilakukan dengan metode kromatografi kolom menggunakan gradien pelarut. Identifikasi senyawa flavonoid dilakukan dengan pereaksi geser pada Spektrofotometri UV. Pengukuran aktivitas antioksidan jahe merah dilakukan dengan metode DPPH (2,2-diphenyl-1-picrylhydrazyl). Pengukuran kadar flavonoid jahe merah dilakukan pada pelarut etanol $96 \%$ serta campuran etanol $96 \%$ dan $\mathrm{HCl} 12 \mathrm{~N}$ dengan perbandingan 98 $: 2 ; 96: 4 ; 94: 6$. Didapatkan kadar flavonoid tertinggi pada jahe merah, yaitu pada campuran pelarut etanol $96 \%: \mathrm{HCl} 12 \mathrm{~N}$ (98:2). Pemisahan senyawa flavonoid menggunakan 21 gradien pelarut, fraksi 12 dan 13 kemudian dilakukan identifikasi dengan pereaksi geser pada Spektrofotometri UV. Uji aktivitas antioksidan ekstrak jahe merah dilakukan dengan menggunakan metode DPPH. Nilai IC50 ekstrak jahe merah adalah $57,14 \mathrm{ppm}$. Kadar flavonoid rimpang jahe merah pada pelarut etanol $96 \%: \mathrm{HCl}$ $12 \mathrm{~N}(98: 2)$ adalah $0,0068 \%$. Identifikasi senyawa flavonoid pada ekstrak jahe merah menunjukkan bahwa senyawa flavonoid yang terdapat pada jahe merah adalah 7-4'dihidroksiflavon. Dengan nilai $I_{50} 57,14$ ppm ekstrak jahe merah termasuk kategori antioksidan kuat.
\end{abstract}

Kata kunci: Jahe merah, flavonoid, antioksidan

\section{Outline}

- Pendahuluan

- Metode

- Hasil dan Pembahasan

- Kesimpulan

- Ucapan Terima Kasih

- Daftar Pustaka 


\section{Pendahuluan}

Zingiber officinale merupakan salah satu tanaman yang banyak digunkan di Asia, Australia dan negara-negara lain. Secara empirik, jahe dapat digunakan sebagai obat sistem pencernaan, sakit kepala, rematik, batuk dan pilek.

\section{Metode}

\section{A. Determinasi Tanaman}

Jahe merah diperoleh dari Kebun Penelitian dan Percobaan Tanaman Manoko, Lembang, Kabupaten Bandung Barat, Jawa Barat. Kemudian jahe merah determinasi tanaman dilakukan di Laboratorium Herbarium Bandungense, Sekolah IImu dan Teknologi Hayati, Institut Teknologi Bandung.

\section{B. Penapisan Fitokimia}

Penapisan fitokimia dilakukan terhadap simplisia dan ekstrak jahe merah dengan menggunakan metode Fransworth ${ }^{1}$.

C. Penentuan Kadar Flavonoid Total Ekstrak Rimpang, Batang, dan Daun Jahe Merah (Zingiber officinale Roscoe Var. Sunti Val)

Metode dilakukan dengan menggunakan metode Christ - Müller dengan modifikasi.

1. Sebanyak $5 \mathrm{~g}$ bagian tanaman jahe merah dimasukkan ke dalam labu bundar, ditambahkan $40 \mathrm{~mL}$ pelarut yaitu etanol $96 \%$ serta campuran etanol $96 \%$ dan $\mathrm{HCl}$ $12 \mathrm{~N}$ dengan perbandingan $98: 2 ; 96: 4 ; 94: 6$ kemudian direfluks selama 30 menit.

2. Setelah direfluks, dibiarkan dingin pada suhu kamar. Ekstrak disaring dan dimasukkan ke dalam labu ukur $100 \mathrm{~mL}$ (larutan A).

3. Residu direfluks kembali dengan $40 \mathrm{~mL}$ pelarut yang sama selama 30 menit. Kemudian dibiarkan dingin pada suhu kamar. Ekstrak disaring (larutan B) dan dimasukkan ke dalam labu ukur $100 \mathrm{~mL}$ (larutan A).

4. Hasil refluks dalam labu ukur $100 \mathrm{~mL}$ digenapkan hingga tanda batas dengan pelarut yang sama dan disebut sebagai larutan stok.

5. Sebanyak $1 \mathrm{~mL}$ larutan stok dimasukkan ke dalam labu ukur $10 \mathrm{~mL}$, ditambahkan 2 $\mathrm{mL}$ larutan $\mathrm{AlCl}_{3} 5 \%$ dan digenapkan oleh air suling hingga tanda batas dan disebut larutan uji.

6. Disiapkan larutan kontras yaitu sebanyak $1 \mathrm{~mL}$ larutan stok dimasukkan ke dalam labu ukur $10 \mathrm{~mL}$ kemudian digenapkan oleh air suling hingga tanda batas.

7. Absorbansi larutan uji terhadap larutan kontras ditentukan dengan spektrofotometer UV-Vis pada panjang gelombang $410 \mathrm{~nm}$.

8. Dilakukan pengukuran absorbansi pada sampel sebanyak tiga kali (triplo).

9. Hasil dinyatakan sebagai persentase kadar flavonoid total dengan menggunakan rumus²:

Keterangan:

$$
K F T=\frac{A \times D F}{A_{1 c m}^{1 \%} \times(w-l d)}
$$

KFT: Kadar Flavonoid Total ; A: Absorbansi sampel; DF: Faktor pengenceran; $A_{1}^{1 \%} \mathrm{~cm}$ : Absorpsi spesifik untuk Rutin - $\mathrm{AlCl}_{3}$ (259.4); w: Berat sampel yang dipakai; Id: Susut pengeringan 
D. Identifikasi Senyawa Flavonoid pada Rimpang Jahe Merah (Zingiber officinale Roscoe Var. Sunti Val)

1. Ekstraksi Flavonoid: $250 \mathrm{~g}$ jahe merah diekstraksi dengan $200 \mathrm{~mL}$ etanol $96 \%: \mathrm{HCl}$ $12 \mathrm{~N}(\mathrm{pH}=1)$ selama 2 jam pada $40^{\circ} \mathrm{C}$ dengan metode refluks. Ekstrak disaring, kemudian residu diekstraksi ulang dua kali, dengan $250 \mathrm{~mL}$ pelarut baru yang sama selama 2 jam. Semua ekstrak dipekatkan dengan rotary vaporator pada suhu $40{ }^{\circ} \mathrm{C}$.

2. Fraksinasi Ekstrak: Kromatografi cair vakum (KCV) dilakukan pada ekstrak etanol pekat yang mengandung senyawa flavonoid. Fase gerak yang digunakan adalah pelarut non-polar ke pelarut polar dengan berbagai rasio dengan fase diam gel silika $\mathrm{H}$. Fraksi yang diduga mengandung flavonoid diidentifikasi menggunakan KLT dengan fase gerak yang digunakan mirip dengan fase gerak untuk ekstrak, kemudian kromatogram diamati dengan sinar UV pada $\lambda 366 \mathrm{~nm}$ dan disemprotkan dengan penampilan noda yang sama untuk ekstrak dan fraksi .

3. Identifikasi Isolat: Identifikasi isolat dilakukan dengan spektrofotometer UV-Vis dengan menggunakan pereaksi geser

4. Uji Aktivitas Antioksidan Rimpang Jahe Merah (Zingiber officinale Roscoe Var. Sunti Val): Konsentrasi sampel uji berupa larutan ekstrak jahe merah, dibuat dengan berbagai konsentrasi yaitu 200, 400,600, 800, 1000 ppm. Dari konsentrasi larutan uji diambil sebanyak $1 \mathrm{~mL}$ lalu ditambahkan larutan DPPH sebanyak $2 \mathrm{~mL}$ ke dalam masing-masing larutan uji, kemudian diinkubasi selama 15 menit dengan suhu $37^{\circ} \mathrm{C}$. Sebagai blanko digunakan ekstrak. Diukur absorbansinya menggunakan spektrofotometer UV-Visible pada panjang gelombang maksimum (Nahar dan Sarker, 2007). Pembanding yang digunakan adalah Vitamin C (asam askorbat) dengan konsentrasi 2, 4, 6, 8, dan 10 ppm.

\section{Hasil dan Pembahasan}

\section{A. Hasil Determinasi}

Berdasarkan surat determinasi no. 712/11.CO2.2/PL/2017 bahwa tanaman yang digunakan adalah jahe merah (Zingiber officinale Roscoe Var. Sunti Val).

\section{B. Hasil Penapisan Fitokimia}

Tujuan penapisan fitokimia adalah untuk mengetahui golongan metabolit sekunder yang terdapat pada simplisia dan ekstrak. Hasil penapisan fitokimia menujukkan bahwa tidak perubahan kandungan metabolit sekunder dari simplisia dan ekstrak. Hal ini membuktikan bahwa metode ekstraksi yang digunakan tidak merubah metabolit sekunder pada simplisia.

Tabel 1. Hasil Penapisan Fitokimia

\begin{tabular}{|c|l|c|c|}
\hline No & \multicolumn{1}{|c|}{ Metabolit Sekunder } & Simplisia & Ekstrak \\
\hline $\mathbf{1}$ & Alkaloid & + & + \\
\hline $\mathbf{2}$ & Flavonoid & + & + \\
\hline 3 & Tanin & + & + \\
\hline $\mathbf{4}$ & Polifenol & + & + \\
\hline 5 & Saponin & + & + \\
\hline 6 & Monoterpen dan Seskuiterpen & + & + \\
\hline
\end{tabular}

Keterangan : $(+)=$ Terdeteksi; $(-)=$ Tidak Terdeteksi 
C. Hasil Penentuan Kadar Flavonoid Total pada Rimpang, Batang, dan Daun Jahe Merah (Zingiber officinale Roscoe Var. Sunti Val)

Kadar flavonoid total tertinggi terdapat dalam rimpang pada campuran pelarut etanol $96 \%$ dan $\mathrm{HCl} 12 \mathrm{~N}$ dengan perbandingan $98: 2$ yaitu sebesar $0,0068 \%$. Hal ini sudah sesuai dengan penggunaan tanaman jahe merah secara empiris, di mana yang digunakan dalam pengobatan adalah bagian rimpangnya.

Campuran pelarut dengan asam bertujuan untuk membantu hidrolisis. Hidrolisis dilakukan untuk membantu menghasilkan aglikon dengan tujuan memberikan data yang konsisten bahwa flavonoid yang diserap hanya sebagai aglikon berdasarkan penelitian Humadi dan Istudor (2008). Metode Christ dan Müller menggunakan reaksi kompleks aglikon dengan $\mathrm{AlCl}_{3}$ sehingga dengan sedikit modifikasi pada metode ini dapat membantu meningkatkan pengambilan aglikon dari simplisia.

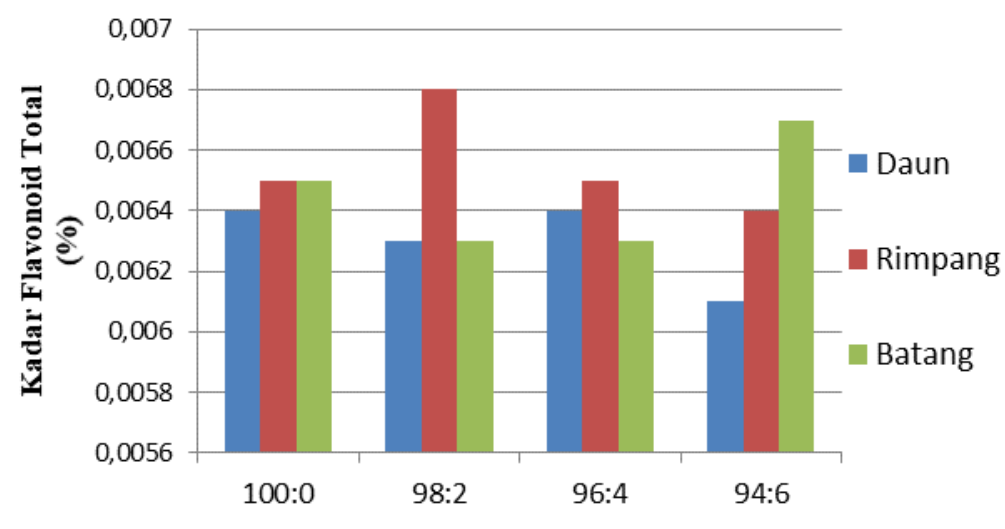

Perbandingan Pelarut Etanol 96\% : HCl 12N

Gambar 1. Grafik Kadar Flavonid Total Jahe Merah

D. Hasil Identifikasi Senyawa Flavonoid pada Rimpang Jahe Merah (Zingiber officinale Roscoe Var. Sunti Val).

Ekstrak kental rimpang jahe merah difraksinasi dengan metode kromatografi cair vakum (KCV) menggunakan 21 pelarut dengan berbagai macam perbandingan. Dari hasil uji identifikasi warna dan kromatografi lapis tipis (KLT) pada fraksi 12 dan 13 dengan menggunakan fase gerak etil asetat : n-butanol (7:3), dapat disimpulkan bahwa kedua fraksi hasil KCV tersebut mengandung flavonoid. Selanjutnya kepada kedua fraksi dilakukan identifikasi senyawa flavonoid dengan pereaksi geser menggunakan spektrofotometer UV.

Tabel 2. Hasil Pengukuran Panjang Gelombang dengan menggunakan Pereaksi Geser

\begin{tabular}{|c|c|c|}
\hline Pereaksi & Pita II (nm) & Pita I (nm) \\
\hline $\mathrm{MeOH}$ & 211,5 & 370 \\
\hline $\mathrm{NaOMe}$ & 219,5 & 376,5 \\
\hline NaOMe 5 menit & 216 & 390,5 \\
\hline $\mathrm{AICl}_{3}$ & 216 & 393 \\
\hline $\mathrm{AlCl}_{3} / \mathrm{HCl}$ & 210 & 394 \\
\hline $\mathrm{NaOAC}$ & 213,5 & 392 \\
\hline $\mathrm{NaOAc} / \mathrm{H}_{3} \mathrm{BO}_{3}$ & 211 & 396 \\
\hline
\end{tabular}


Sehingga, dari hasil interpretasi perubahan panjang gelombang pada fraksi 12 dan 13 hasil KCV dapat disimpulkan bahwa senyawa flavonoid yang terdapat pada rimpang jahe merah adalah 4',7-dihidroksiflavonol.<smiles>O=c1cc(-c2ccc(O)cc2)oc2cc(O)ccc12</smiles>

Gambar 2. 4',7-dihidroksiflavonol

E. Hasil Uji Aktivitas Antioksidan Rimpang Jahe Merah (Zingiber officinale Roscoe Var. Sunti Val).

Tabel 3. Hasil Pengukuran \% Aktivitas Antioksidan Ekstrak Jahe Merah dan Vitamin C terhadap DPPH

\begin{tabular}{|c|c|c|}
\hline Sampel & $\begin{array}{c}\text { Konsentrasi } \\
\text { (ppm) }\end{array}$ & $\begin{array}{c}\text { \% Aktivitas } \\
\text { Antioksidan }\end{array}$ \\
\hline Vitamin C & 2 & 47,5 \\
& 4 & 71,3 \\
& 6 & 73,6 \\
\hline & 10 & 89,9 \\
Ekstrak Jahe & 20 & 97,4 \\
\hline Merah & 40 & 45,75 \\
& 60 & 48,88 \\
& 80 & 49,88 \\
& 100 & 52,12 \\
\hline
\end{tabular}

Aktivitas antioksidan dari ekstrak lebih rendah dari vitamin $C$ sebagai kontrol positif, karena ekstrak bukan senyawa murni. Ekstrak mengandung flavonoid, tanin, dan alkaloid. Semua struktur ini memiliki gugus hidroksil yang dapat menyumbangkan hidrogen untuk berinteraksi dengan radikal DPPH untuk menghasilkan DPPH-H.

Antioksidan alami dari tanaman obat adalah pilihan yang baik untuk mengendalikan stres oksidatif. Karena berasal dari alam, senyawa ini biasanya tidak beracun. Antioksidan saat berinteraksi dengan radikal DPPH mentransfer proton ke radikal DPPH dengan abstraksi langsung atom $\mathrm{H}$-fenol dan proses transfer elektron, sehingga menetralkan karakter radikal bebasnya, yang menghasilkan DPPH-H (2,2-diphenyl-1picrylhidrazyn), yaitu DPPH dengan reaktivitas lebih sedikit.

\section{Kesimpulan}

1. Kadar flavonoid total rimpang jahe merah paling tinggi terdapat pada campuran pelarut etanol $96 \%$ dan $\mathrm{HCl} 12 \mathrm{~N}$ dengan perbandingan $98: 2$, yaitu sebesar $0,0068 \%$.

2. Identifikasi isolat pada fraksi gabungan (12 dan 13) dengan pereaksi geser menggunakan metode spektrofotometri UV menunjukkan senyawa 7,4'dihidroksiflavonol. 
3. Nilai $I_{C_{50}}$ ekstrak etanol rimpang jahe merah adalah $57,14 \mathrm{ppm}$. Nilai $\mathrm{IC}_{50}$ yang lebih kecil dari $200 \mu \mathrm{g} / \mathrm{mL}$ menunjukkan bahwa ekstrak jahe merah termasuk kategori antioksidan kuat.

\section{Ucapan Terima Kasih}

Penulis mengucapkan terimakasih kepada Yus Hargono, Syumillah Saepudin, Novi Herliani dan Gisya Maulidita atas bantuan teknisnya pada penelitian ini

\section{Daftar Pustaka}

1. Ahuja, J., Suresh, J., Deep, A., Madhuri., Pratyusha., dan Ravi., 2011., Phytochemical Screening of Aerial Parts Of Artesmisia parviflora Roxb.: A medical plant., Der Phamacia Letre, 3 (6) : 116 - 124.

2. Departemen Kesehatan Republik Indonesia., 1978. Materia Medika Indonesia jilid II, Jakarta: Depkes RI. Hal 150-156, 165-167.

3. Departemen Kesehatan Republik Indonesia., $1995 \mathrm{RI}$, 1995., Farmakope Indonesia Edisi IV., Departemen Kesehatan., Jakarta., Hal 1036 dan 1403.

4. Dina Mulyana Syafitri, Jutti Levita, Mutakin Mutakin, Ajeng Diantini, A Review: Is Ginger (Zingiber officinale var. Roscoe) Potential for Future Phytomedicine? I J A $S$ Vol. 8 Nomor 1 Edisi April 2018

5. $\quad$ Fernandes, A.J.D., Ferreira, M.R.A., Randoau, K.P., Souza and Soares., 2012., Total Flavonoids Content in the Raw Material and Aqueous Extractives from Bauhinia monandra Kurz (Caesalpiniaceae)., The Scientific World Journal Vol. 2012.

6. Fransworth, N. R. 1996. Biological and Phytochemical Screening of Plants.

7. Harborne, J. B. 1987. Metode Fitokimia : Penuntun Cara Modern Menganalisin Tumbuhan. Terbitan kedua Bandung : Penerbit ITB, Hal 70 ; 147-148; 243-235

8. Mabry, T. J., Markham. K. R., dan Thomas, M. B., 1970., The Systematic Identification of Flavonoids., New York: Springer-Verlag.

9. Margaretta, S dan Handayani, SD., 2011., Cara Mengidentifikasi Flavonoid. Terjemahan Kosasih Padmawinata., Bandung: Institut Teknologi Bandung.

10. Markham, K. R., 1988., Cara Mengidentifikasi Flavonoid. Terjemahan Kosasih Padmawinata., Bandung: Institut Teknologi Bandung.

11. Sutrisno, H. (2000). Metodologi Research. Yogyakarta : Andi Yogyakarta.

12. Winarsi, H. 2007. Antioksidan Alami dan Radikal Bebas, Yogyakarta: Penerbit Kanisius. Hal. 12-20, 274,275,128

13. Windono, T. Soediman, S. Yudawati, U. Ermawati, E. Srielita, Erowati, T.I. (2001). "Uji Peredam Radikal Bebas Terhadap 1,1-Diphenyl-2-Picrylhydrazyl (DPPH) dari ekstrak kulit buah dan biji anggur (Vitis vinivera L). Probolinggo Biru dan Bali”. Artocarpus. Surabaya 1(1), 34-43. 